\title{
The Central Role of Philosophy in a Study of Community Dialogues
}

Michele S. Moses, University of Colorado Boulder

Lauren P. Saenz, Boston College

Amy N. Farley, University of Colorado Boulder

\author{
Revised Article Submission for "Philosophical Enquiry through Empirical Research" \\ Special Issue of Studies in Philosophy and Education \\ Guest editors: Doris A. Santoro \& Terri S. Wilson
}

February 15, 2014

Contact: Michele S. Moses, michele.moses@colorado.edu 


\begin{abstract}
The project we highlight in this article stems from our philosophical work on moral disagreements that appear to be - and sometimes are - intractable. Deliberative democratic theorists tout the merits of dialogue as an effective way to bridge differences of values and opinion, ideally resulting in agreement, or perhaps more often resulting in greater mutual understanding. Could dialogue mitigate disagreements about a controversial education policy such as affirmative action? Could it foster greater understanding? We conceived of a project that would simultaneously fulfill two goals that we had as philosophers, education researchers, and aspiring public intellectuals. First, it would allow us to use philosophy in research, grounding our mixed methods research in a philosophically informed framework. The tools and analytic techniques that are particular to philosophers felt uniquely suited for an empirical study concerning political theory. Second, we aimed to use philosophy in the community. We were able to put our own expertise in philosophy and race-conscious education policy to good use by purposefully creating opportunities for diverse community members in our larger metropolitan area to engage in dialogue and deliberation with each other over the issue of affirmative action. Introduction and Background

Questions of method tend to occupy philosophers of education (see for example, Burbules \& Warnick 2006; Moses 2002; Ruitenberg 2009, as well as many others). Indeed, they are questions that consume other philosophers, as well; consider, for example, Rorty's distinction between systematic and edifying philosophy (Rorty 2009/1979). Philosophers of education often face the task of applying or using philosophical tools to get at questions and problems in education policy and practice.
\end{abstract}


In a previous examination of a morally controversial education policy, we aimed to use deliberative democratic theory to make the case that education scholars and researchers - that is, experts in particular policy issues - have a responsibility to take action and share their work in the community, especially when members of the public have the opportunity to participate in collective decision-making about education policy (see Saenz \& Moses 2010). In the process of making such an argument, however, we came to see that our philosophical inquiry and argumentation would be both complemented and strengthened by empirical data. For example, we used qualitative media analysis in an examination of the discourse surrounding Proposal 2, Michigan's 2006 anti-affirmative action ballot initiative. We couldn't claim that the media were providing the public with fair and accurate information about an important and thorny education policy issue without studying what, in fact, the media said about that issue to see if our intuitive claim was indeed supported by the available evidence (it was).

As three scholars immersed both in philosophy of education and education policy studies, we discovered that deliberative democratic theory provides a helpful framework for understanding how persons come to understand their own views and beliefs about morally controversial education policy issues. However, even as the tenets of deliberative democratic theory seemed - on the whole - quite obviously right to us, we realized that there was little empirical work providing evidentiary support for our belief that using deliberation as a tool in communities would clarify provocative education policy issues, and in turn help people make better decisions about those policies when they were up for popular vote. The particular case we had in mind was affirmative action policy, which would be eliminated in our state (Colorado) if a particular anti-affirmative action state ballot initiative known as Amendment 46 were to pass. Moses (2006) has written about affirmative action as a morally contentious policy, one that 
provokes moral disagreements stemming not only from factors such as racism, but also from differing conceptions of democratic ideals such as equality, liberty, and diversity. These in turn are the result of profound theoretical disagreements between those who believe that democratic ideals require equal opportunity policies like affirmative action and those who believe that similar or parallel ideals require abolishing them.

In the context of Colorado's impending vote in 2008, we conceived of a project that would simultaneously fulfill two goals that we had as philosophers, education researchers, and aspiring public intellectuals. First, it would allow us to use philosophy in research (Moses 2002), grounding our mixed methods research in a philosophically informed framework. The tools and analytic techniques that are particular to philosophers felt uniquely suited for an empirical study concerning political theory. Second, we aimed to use philosophy in the community. We were able to put our own expertise in philosophy and race-conscious education policy to good use by purposefully creating opportunities for diverse community members in our larger metropolitan area to engage in dialogue and deliberation with each other over the issue of affirmative action (Davidson \& Moses 2012).

These two goals exemplify how we see our work as philosophically oriented empirical research, allowing us to bring philosophy to bear on contested education policy issues. The project we highlight in this article stems from our philosophical work on moral disagreements that appear to be - and sometimes are - intractable. Deliberative democratic theorists tout the merits of dialogue as an effective way to bridge differences of values and opinion, ideally resulting in agreement, or perhaps more often resulting in greater mutual understanding. Our project essentially tested this premise: could dialogue mitigate disagreements about affirmative action? Could it foster greater understanding? Our research team set out to investigate these 
questions, especially as related to how dialogue participants understood and justified affirmative action. Toward this end, we organized community dialogues in the fall of 2008, just before the election, to help community members learn about and discuss affirmative action policy in Colorado.

Beyond these empirical questions, we also are interested in the relationship between philosophical investigation and broader methodological issues in educational research. Can philosophic principles be operationalized in more traditional empirical studies? How might mixed methods approaches be enhanced by philosophy?

Policy Context

To this date, voters in six states - California, Washington, Michigan, Nebraska, Arizona, and Oklahoma ${ }^{1}$ - have approved ballot initiatives that ban affirmative action in higher education admissions and effectively curtail policies designed to promote equality of educational opportunity. This scenario is becoming increasingly familiar: Voters in states across the country are given the opportunity to decide contentious education policy issues through a direct democratic process. In 2008, Coloradans voted on an identical ballot initiative - Amendment 46 - intended to end affirmative action in the state. For this reason, we urgently wanted to help people gain understanding of the relevant issues, and we saw that desire as an opportunity to explore the relationship between philosophical inquiry and empirical research. Ultimately, Colorado voters became the first (and only) state to defeat an anti-affirmative action ballot measure. Nevertheless, the debate surrounding affirmative action is far from settled on the national stage: in June 2013, the Supreme Court issued a ruling in Fisher v. the University of Texas, affirming the constitutionality of race-based affirmative action in higher education, but 
placing a larger burden on institutions to withstand strict scrutiny regarding the necessity of such policies.

Education policies that have been placed on state ballots often impact minority populations directly (Gamble 1997; Moses \& Farley 2011; Sabato, Ernst, \& Larson 2001). Yet they are decided by majoritarian democratic processes: whereas in the past these policies were determined by "experts" thought to possess deep knowledge of the issues - educators, policymakers, and political representatives - citizens now hold the power (and responsibility). This shift in policymaking responsibility from experts to citizens means that in order to promote just policy decisions, voters should have access to meaningful information about the policy. While some researchers argue whether the increasing role of the public in policy decisions is a good thing for democracy (Bowler \& Donovan 2000; Gerber 1999; Moses \& Farley 2011; Moses \& Saenz 2008; Smith \& Tolbert 2004), there is a need for scholars (that is, experts), to contribute information to the public.

As such, our study was conceived with two purposes: (1) to investigate how scholarfacilitated community dialogues on affirmative action may affect dialogue participants' affirmative action knowledge, beliefs, and voting behavior; and (2) to bring scholarly expertise to bear on affirmative action policy, as voters in our state prepared to decide on an antiaffirmative action ballot initiative. In this article, we describe the design, implementation, and findings of this empirical study, in order to illustrate our broader argument about the promise of conducting philosophically informed empirical research. We aim to make sense of how our philosophical work not only informed our empirical research, but also undergirded our research design and data analysis. Indeed, without philosophy, it is unclear whether our research project could have even taken place, or, perhaps, could have taken place in quite the same way. Beyond 
grounding social science research in a philosophical framework, our philosophical perspectives shaped each part of this project from conception to completion. Our philosophical lens allowed us to understand the contested policy issue as a moral disagreement (Moses 2006), which in turn fostered our interest in creating community dialogue opportunities in which participants might gain increased understanding of the issue and their own beliefs. Our emphasis on clarifying dialogues, rather than say, deliberation toward consensus decision-making, was a result of our grounding in philosophy.

Our findings include analyses of data from dialogue participant questionnaires and follow-up interviews. Through the questionnaires, participants responded to questions regarding their opinions, knowledge, and beliefs about affirmative action. From the questionnaires and interview data sources, we wanted to learn how participation in community dialogues may affect participants' knowledge and beliefs about affirmative action and their political decision-making about affirmative action policy. Both our instrumentation (survey items and interview questions) and our analytic approaches draw strongly on philosophy. In designing instruments, we constructed individual items to reflect various philosophical views on affirmative action. That is, rather than framing affirmative action as a case of "good" versus "bad" policy, we used language that mirrors a range of justice-oriented moral arguments (i.e., "Affirmative action unfairly discriminates against White people"). These norms also shaped our analytic approach by providing general categories to guide our thematic coding. Additionally, we operated under the assumption of deliberative democratic theory that knowledge is a prerequisite for making informed policy decisions; this led us to treat "affirmative action knowledge" as a primary construct of interest and pre-post outcome in our study. 
In what follows, we first situate this topic in the literature on the impact of deliberative dialogues like those conducted in this study. We explain the theories that guided our data collection and analysis, as well as the methods used. Overall, we found that deliberative dialogues have the potential to educate participants on the substantive issues related to the moral disagreement about affirmative action. In general, participants learned new information and grew in their understanding of affirmative action policy - although this differed by participants' race and age - and their attitudes toward affirmative action became more positive overall. Many participants also indicated that their experience influenced their personal decision about Amendment 46, and that they would be more likely to engage in further deliberation on policy issues as a result of the dialogue experience. Ultimately, participants also indicated that the deliberative experience was positive, although overall satisfaction was positively related to predialogue attitudes toward affirmative action (see Davidson \& Moses 2012 for related analyses of these data).

\section{Theoretical Perspectives}

According to Amy Gutmann and Dennis Thompson's (1996; 2004) theory of deliberative democracy, public deliberation on social policy issues is a necessary good. Social policies such as affirmative action almost always involve some form of public moral disagreement; this is inevitable in a pluralist democracy. The design of our study and subsequent analyses relied on deliberative democratic theory. Deliberative democratic theorists pose an alternative to either aggregative or participatory democracy, arguing that citizens and society benefit from a deliberative process when they are confronted with moral disagreements (Cohen 1997; Gutmann \& Thompson 1996; 2004). Democratic deliberation requires citizens to present their beliefs and arguments in a public setting; individuals challenge one another and are challenged. In short, 
they come to understand and refine their own beliefs in the face of these challenges, as they articulate them to others. Through structured community dialogues, we aimed to put Gutmann \& Thompson's theories into practice, by asking community members to engage in a facilitated deliberation about affirmative action and share their beliefs and values with a range of community members. Our philosophical interests led us to test both the feasibility and the implications of operationalizing deliberative democratic theory. That is, we attempted to create a setting built on a number of deliberative democratic principles, in order to explore a controversial moral issue, with the intent of describing and analyzing the implementation and impact of such an approach.

Typically, deliberative democratic theory is applied in the context of collective decisionmaking, in situations in which groups are asked to find common ground and come to a mutually acceptable decision (Benhabib 1996). Our dialogues did not require a decision by the group; they attempted to provide both information and a space within which people could present their reasons and arguments in a public setting, as part of a deliberative democracy. This way, participants would gain valuable information about affirmative action policy that they could then use to inform their individual voting decision on Amendment 46. The Amendment 46 vote provided a unique context for several reasons. First, it is an issue for which there exists contentious, moral disagreement, and, second, relatively non-expert citizens were being asked to decide individually on a race-conscious education policy that directly affects their fellow citizens. As such, there is a direct policy consequence from these ballot initiative votes.

Deliberative democratic theory traditionally has maintained what Button \& Ryfe (2005) called a "normative thrust toward consensus and mutual agreement" (p. 29). The design of our community dialogues altered the course of the "normative thrust" away from collective decision- 
making and toward educative dialogue, reason giving, and public information. Participants were not asked to arrive at a compromised, mutual decision; rather, they were offered the opportunity to express their opinions and knowledge on a policy matter that affects the greater public. This was an intentional shift, designed not to move away from normative conceptions of deliberative democracy but to explore its educative effects in public settings. Thus, we focused not just on the potential outcomes of democratic deliberation, but also on its intrinsic value (which, in the end, may prove to be an outcome as well).

A deliberative perspective encourages greater public participation in and understanding of public policy debates by demanding that citizens abide by the principles of reciprocity, publicity, and accountability. The primary principle of reciprocity fosters policy discussions and debates that are respectful, inclusive, and that encourage deeper understanding of the content of moral disagreements; in a sense, it sets the ground rules for deliberation. We too endeavored to apply these ideals to a real-world deliberative dialogue in the community.

Deliberative democracy supports expanded decision-making in the public and private sphere by bringing together constituents and asking individuals to offer public reasons for their views. The ballot initiative process risks narrowing decision-making to the private sphere. Voters most often deliberate and decide privately; hence their arguments are rarely exposed to public deliberation. Following deliberative democratic theory (Gutmann \& Thompson 1996; Young 1996), our research was grounded in the idea that public deliberation is necessary when initiatives are put to a popular vote in order to foster a more informed voting public and greater mutual understanding across moral disagreements, with the goal of promoting effective, equitable education policy. 
Deliberative democracy in practice is fertile ground for both philosophical and empirical research, and can provide a model for future avenues of similar research. Up until the last decade or so, however, these fields have evolved separately (Barabas 2004). Recent empirical investigations have examined the feasibility of applied deliberative democracy, but tensions remain. Significant difficulties exist, for example, in implementing the normative principles of deliberative democracy in practical settings (Button \& Mattson 1999). Yet there is a growing body of literature suggesting the civic benefits of deliberative engagement. For example, Barabas (2004) found that structured deliberation about Social Security increased participants' knowledge and shifted opinions about topical issues. Others have found large-scale applications of deliberative practice feasible and effective (e.g., Weeks 2000). Taken as a whole, the results of the research literature on deliberation are complex. Consider that Barabas (2004) found that deliberation indeed increased issue knowledge, but this was dependent upon the quality of the comments and participants' ability to be open-minded. Some studies have shown that participants can end up more anxious and frustrated, or less open to other viewpoints (Ryfe 2005; Schkade, Sunstein, \& Hastie 2007). Ryfe (2005) noted that people can walk away from the same deliberation with different senses of how it went, and that is because it involves an assessment of one's self in relation to others. In addition, political power, social status, or self-interest often operate within dialogue sessions (Andersen \& Hansen 2007; Davidson \& Moses 2012; Mendelberg \& Oleske 2000). These issues seem likely to affect if and how participants learn from their deliberative experiences. The study highlighted here suggests that while these practical concerns are not without validity, the principles of deliberative democracy can be operationalized in publically useful ways. 
Our results both support and complement the findings of previous studies. For example, Smith \& Wales' (2000) study of a citizen jury in the United Kingdom showed changes in preferences to be widespread, as well as strong effects on political understanding and participation. Our study suggests that participants also gained political issue knowledge. This underscores the idea that deliberative dialogues have significant promise of positive effects, whether the outcomes are related to increased understanding, democratic participation, or political decision-making (Button \& Ryfe 2005). We are also interested in the cumulative effects of deliberation; our data suggest that if individuals find deliberative opportunities worthwhile (i.e., they learn new information), they may seek out more such opportunities. Researchers have begun to document what can be considered the secondary effects of deliberative engagement: transforming public opinions and behaviors, changing public officials' opinions and behaviors, and impacting strategic political choices (see, e.g., Burkhalter, Gastil, \& Kelshaw 2002; Delli Carpini, Cook, \& Jacobs 2004; Gastil 2008). More research is needed on the long-term impacts of deliberation. In particular, philosophically-informed empirical investigations of deliberative democracy can help to clarify the conditions for its successful implementation.

\section{Data Sources and Methods}

In designing the dialogues for this project, we drew from several models, including the National Issues Forum (2008), the Public Conversations Project (2006; Herzig \& Chasin 2006), and ChoiceDialogues (Fishkin \& Rosell 2004). We included the common elements across all three: Well-trained facilitators, small-group dialogue sessions, and specific, relevant, "expert" information to which all participants had access.

Toward this end, a group of nine education scholars (led by and including the authors) organized and facilitated a dozen community dialogues throughout the Denver-Boulder 
metropolitan area in the two months prior to the 2008 election. The dialogues addressed affirmative action policy, the fate of which would be decided collectively by voters on Amendment 46. We undertook a mixed method case study research design, with each dialogue representing a "case" to be studied as an individual unit and as a part of the whole, in order to understand the larger impact of deliberative democratic dialogue on political knowledge and decision-making.

Throughout the dialogue, participants were asked to share their experiences; question and challenge themselves and each other; and grapple meaningfully with the content, philosophies, and potential effects of affirmative action. Participants were also asked to agree to a set of ground rules to guide their conversations (i.e., listening respectfully, speaking for themselves and allowing others to do the same, not criticizing the views of others). As mentioned above, our primary interest was not reaching consensus, but rather improving the quality of public dialogue on affirmative action by providing citizens with substantive information and offering them the space and tools with which to engage in democratic deliberation.

\section{$\underline{\text { Study Findings and Discussion }}$}

Detailed findings from this study have been reported in a previous publication (Davidson \& Moses 2012). In general, we explored outcomes and relationships among three areas of focus: (a) participant knowledge regarding affirmative action, (b) participant attitudes toward affirmative action, and (c) political participation and decision-making.

Affirmative action knowledge. In general, participants entered the dialogues very knowledgeable about affirmative action: The typical participant was able to correctly answer approximately five out of seven questions about affirmative action policies, rules, and constitutional limitations. In follow-up interviews, many participants further indicated that they 
came to the dialogues because affirmative action was a policy about which they were particularly passionate.

Affirmative action beliefs and attitudes. Dialogue participants arrived with varying beliefs about affirmative action. Across all participants, there was a small positive change between the pre- and post-questionnaire, although the magnitude of this change is not likely to be considered practically significant.

Political participation and decision-making. Overall, participants indicated that they learned new information and perspectives because of the dialogues, and more than half of participants reported changed views on affirmative action. This pattern held regardless of prior knowledge or reported knowledge growth, or the reported quality of their deliberative experience. In participant interviews, few indicated that the dialogue caused them to change their vote on Amendment 46, but more than a third stated that their dialogue participation had impacted their vote in some way.

Participants also reported that they discussed their dialogue experiences with others, including both the policy- and deliberation-related aspects of the forum. For example, one participant described leading her extended family in a lively discussion about Amendment 46 following her participation in the dialogue. Another participant mentioned her intent to initiate a series of deliberative dialogues in her own community. These examples provide some evidence toward the claim that the impact does not end when the formal deliberation ends. Their impact may be diffuse and spreading and, admittedly, hard to pinpoint. It is apparent, however, that the dialogue participants were not the only people affected.

In total, our findings suggest that the community dialogue experience served to expand participants' knowledge about affirmative action policy, and that the majority of participants 
reported a more favorable view of affirmative action policy following the forum. Despite the general favorable outcome, participants also reported that the dialogue experience served to galvanize group views, particularly when there was a strong majority within a particular dialogue session. In addition, we noted - both in our experience as facilitators and in follow-up analysis of dialogue videos and transcripts - the power of dialogue participants with perceived expertise; even when the information shared by a participant with perceived expertise was incorrect, other participants seemed to internalize the information. Finally, findings from follow-up interviews suggest that a majority of our interview participants voted to preserve affirmative action in Colorado, regardless of whether they entered the community dialogue session with negative or favorable views about affirmative action.

Perhaps more importantly, our data on political participation and decision making suggest that these processes are too complex to be captured by a few survey or interview questions begging the need for mixed methods approaches to deliberative dialogue. Although the participants generally believe the dialogues were helpful as they considered Amendment 46, and some even changed their intended vote as a result, the mechanism at work is hard to tease out. What exactly pushes people to reconsider their views? Research-based information? Hearing others' perspectives? Revisiting deeply held assumptions? It seems to be some combination of at least these three ideas. And while the exact impact of the dialogues remains unclear, it is clear that participants felt pushed to think more deeply about the issue, even if they came into the experience with firm beliefs.

Several of our quantitative findings point to common difficulties that arise when attempting to put deliberative principles into action. Despite the relative demographic diversity of our participant sample, our sample was small and the majority came with positive attitudes 
about affirmative action. Though we strove to be as inclusive as possible, the reality was that affirmative action supporters were seemingly more attracted to the dialogues in the first place. Most troubling is the fact that participants' prior level of support for affirmative action is positively correlates with the quality of their deliberative experience, indicating that affirmative action supporters were more likely to have a positive experience. This finding was corroborated in interviews with participants, where it became clear that one major impact of the dialogues was to reinforce or galvanize pre-existing beliefs about affirmative action. This galvanizing effect, identified by Schkade, Sunstein, and Hastie (2007) as "ideological amplification" (p. 917), can seriously impact the deliberative aspect of the dialogue. Not only do participants in the majority take fewer risks due to the comfort factor, those in the minority can feel attacked or singled out.

\section{Conclusions}

The example of philosophically informed empirical research we share herein highlights the idea that scholars have an important responsibility to provide not only credible information but also helpful spaces, structures, and guidance for weighing and evaluating that information in light of personal experience and belief, to help advance public deliberation about education issues (Davidson \& Moses 2012; Wachbroit 1998). ${ }^{2}$ This is even more important if and when the public's role in deliberations over education policy is expanded through direct democratic initiatives. Public deliberation over critical issues can function to clarify contested values, increase public understanding, foster people's willingness to reconsider their own views, and increase communication between opposing sides on a given issue. People need to hear both datarelated and values-related information about disputed policies. This is especially important for education research and policies that appeal to values that can be divisive and misunderstood. 
From a methodological perspective, this study offers compelling examples of the many ways in which philosophy can enhance empirical research. Our commitment to integrating philosophy and research allowed us to test the feasibility of normative deliberative democratic theory in practice, finding support for its application in the public realm of affirmative action policy. In addition, by explicitly embracing and reflecting on the philosophical roots of our research approach, we challenge the positivist tradition of "neutral" social science research while also exploring observable trends and outcomes in the context of education policymaking. The mixed methods nature of our research also allowed us to use philosophy in multiple ways: our quantitative outcomes were determined by philosophical analysis, while our qualitative analyses drew on this initial philosophical framework. Integrating quantitative and qualitative data and analysis throughout the process strengthened our understanding of how participants' views changed and were affected by the deliberative process; these understandings would have felt incomplete from a monomethod approach.

As our study highlights, democratic deliberation by way of community dialogues allows citizens to voice their thoughts, concerns, beliefs, and arguments publicly, to hear alternative perspectives, and to consider policy in light of its effect on others or on a community. Deliberative dialogues also hold the potential to be educational spaces in which citizens learn more about controversial issues, like affirmative action, that are prone to moral disagreement.

Our experience tells us that deliberative community dialogues on controversial political issues are not just possible; they actually foster an informed, participatory democracy. Wellinformed citizens become well-informed voters, who in turn are likely to make well-reasoned and deliberative decisions about education policy. The model we used can serve as a framework for future deliberative dialogues, and we can continue to refine the model to make it more 
inclusive and useful for citizens who wish to be more informed in their political life. Our results affirm that small group dialogues can contribute to participants' greater information and understanding about a given controversial education policy issue, in this case affirmative action. Consequently, we recommend that education scholars, and in particular philosophers of education, make greater efforts to bring their expertise into the community and public arena through various venues, including public community dialogues. When necessary, philosophers of education interested in pursuing such work can partner with other scholars trained in qualitative and quantitative research methods. Nevertheless, such dialogues are effective ways for philosophical scholars to engage with members of the public, share philosophically informed policy information as well as their expertise, and contribute to society's deliberative democratic aims. 


\section{References}

Andersen, V.N. \& Hansen, K.M. (2007). How deliberation makes better citizens: The Danish Deliberative Poll on the Euro. European Journal of Political Research, 46, 531-556.

Barabas, J. (2004). How deliberation affects policy opinions. American Political Science Review, 98(4), 687-701.

Benhabib, S. (1996). Toward a deliberative model of democratic legitimacy. In S. Benhabib (Ed.), Democracy and difference: Contesting the boundaries of the political (pp. 67-94). Princeton: Princeton University Press.

Bowler, S. \& Donovan, T. (2000). Demanding choices: Opinion, voting, and direct democracy. Ann Arbor: University of Michigan Press.

Burkhalter, S., Gastil, J., \& Kelshaw, T. (2002). The self-reinforcing model of public deliberation. Communication Theory, 12(4), 398-422.

Burbules, N.C. \& Warnick, B.R. (2006). Philosophical inquiry, In G. Camilli, P. Elmore, \& J. Green (Eds.), Complementary Methods for Research in Education (pp. 489-502). Washington, D.C.: American Educational Research Association.

Button, M. \& Mattson, K. (1999). Deliberative Democracy in Practice: Challenges and Prospects for Civic Deliberation. Polity 31(4), 609-637.

Button, M. \& Ryfe, D.M. (2005). What can we learn from the practice of deliberative democracy? In J. Gastil \& P. Levine (Eds.), The deliberative democracy handbook; Strategies for effective civic engagement in the $21^{\text {st }}$ century (pp. 20-34). San Francisco, CA: Jossey-Bass.

Cohen, J. (1997). Deliberation and democratic legitimacy. In J. Bohman \& W. Rehg (Eds.), Deliberative democracy: Essays on reason and politics (pp. 67-91). Cambridge, MA: The MIT Press.

Davidson, K.L. \& Moses, M.S. (2012). Speaking across difference in community dialogues on affirmative action policy. Equity and Excellence in Education, 45(1), 217-236.

Dellicarpini, M.X., Cook, F.L., \& Jacobs, L.R. (2004). Public deliberation, discursive participation, and citizen engagement: A review of the empirical literature. Annual Reviews of Political Science 7, 315-344.

Fishkin, J.S. \& Rosell, S.A. (2004). ChoiceDialogues and deliberative polls: Two approaches to deliberative democracy. National Civic Review, pp. 55-63.

http://www.viewpointlearning.com/wpcontent/uploads/2011/04/deliberative_democracy_w04.pdf Accessed 15 September 2011. 
Gamble, B.S. (1997). Putting civil rights to a popular vote. American Journal of Political Science, 41, 245-269.

Gastil, J. (2008). Political communication and deliberation. Thousand Oaks, CA: Sage.

Gerber, E. R. (1999). The populist paradox: Interest group influence and the promise of direct legislation. Princeton, NJ: Princeton University Press.

Gutmann, A. \& Thompson, D. (1996). Democracy and disagreement. Cambridge, MA: Belknap.

Gutmann, A. \& Thompson D. (2004). Why deliberative democracy? Princeton: Princeton University Press.

Herzig, M. \& Chasin, L. (2006). Fostering dialogue across divides: A nuts and bolts guide from the Public Conversations Project. Public Conversations Project. http://www.publicconversations.org/docs/resources/Jams_website.pdf Accessed 15 September 2011.

Mendelberg, T., \& Oleske, J. (2000). Race and public deliberation. Political Communication, 17, 169-191.

Moses, M.S. (2002). The heart of the matter: Philosophy and educational research. Review of Research in Education, 26, 1-21.

Moses, M.S. (2006). Why the affirmative action debate persists: The role of moral disagreement. Educational Policy, 20(4), pp. 567-586.

Moses, M.S. \& Farley, A.N. (2011). Are ballot initiatives a good way to make education policy?: The case of affirmative action. Educational Studies, 47(3), 260-279.

Moses, M.S. \& Saenz, L.P. (2008). Hijacking education policy decisions: The case of affirmative action. Harvard Educational Review, 78(2), 289-310.

National Issues Forum (2008). http://www.nifi.org/index.aspx Accessed 15 September 2011.

Public Conversations Project (2006). Constructive conversations about challenging times: A guide to community dialogue; and Fostering dialogue across divides. Public Conversations Project. http://www.publicconversations.org/resources/constructive-conversations-aboutchallenging-times-guide-community-dialogue-version-50

Accessed 15 September 2011.

Rorty, R. (2009/1979). Philosophy and the Mirror of Nature. Princeton, NJ: Princeton University Press.

Ruitenberg, C. (2009). (Ed.). Special Issue: What do Philosophers of Education do? (And how do they do it?). Journal of Philosophy of Education, 43(3). 
Ryfe, D.M. (2005). Does deliberative democracy work? Annual Review of Political Science, 8, 49-71.

Sabato, L., Ernst, H. \& Larson, B. (2001). A call for change: Making the best of initiative politics. In L. Sabato, H. Ernst, \& B. Larson (Eds.), Dangerous democracy? (pp. 179-190). Lanham, MD: Rowman \& Littlefield.

Saenz, L.P. \& Moses, M.S. (2010). Deliberating about affirmative action: Linking education policy research and the media. American Journal of Education, 116(2) (pp. 263-287).

Schkade, D., Sunstein, C.R., \& Hastie, R. (2007). What happened on deliberation day? California Law Review, 95(3) Cal. L.Rev. 915-940.

Smith, D.A., \& Tolbert, C. (2004). Educated by initiative: The effects of direct democracy on citizens and political organizations in the American states. Ann Arbor, MI: University of Michigan Press.

Smith, G. \& Wales, C. (2000). Citizens' juries and deliberative democracy. Political Studies, 48, 51-65.

U.S. Census Bureau. (2010). Boulder County, Colorado. State and County Quick Facts. http://quickfacts.census.gov/qfd/states/08/08013.html Accessed 15 September 2011.

Wachbroit, R. (1998). Public deliberation and scientific expertise. Philosophy and Public Policy, $18(4), 17$.

Weeks, E.C. (2000). The practice of deliberative democracy: Results from four large-scale trials. Public Administration Review, 60(4), 360.

Young, I.M. (1996). Communication and the other: Beyond deliberative democracy. In S. Benhabib (Ed.), Democracy and difference: Contesting the boundaries of the political, (pp. 120-135). Princeton: Princeton University Press. 
${ }^{1}$ These initiatives passed in 1996 (CA), 1998 (WA), 2006 (MI), 2008 (NE), 2010 (AZ) and 2012 (OK).

${ }^{2}$ We thank one of the anonymous reviewers for suggesting we expand this point. 